\title{
16 Harnessing ecosystem services in transforming agriculture in Southern Africa
}

\author{
Barbara Gemmill-Herren, Florence Mtambanengwe, \\ Paul Mapfumo, Gisèle L. Herren, Tlou S. Masehela, \\ Philip C. Stevenson and Jeremy K. Herren
}

\section{Introduction}

Southern Africa is a region that is extraordinarily rich in natural resources and biodiversity and is equally an area of striking food insecurity. Agriculture in Southern Africa has evolved over tens of thousands of years, and for most of this time it has been small-scale, labour intensive and low-tech. Over the last halfcentury or more, however, new forms of agriculture have emerged which make extensive use of inputs - improved seeds, fertilizers and pesticides - to increase production to meet the food needs of a growing global population. But there is growing evidence that these agricultural techniques - both in rich and poor countries - are helping to undermine the natural resource base of the communities and economies that depend upon them, including extensive degradation of soils (IPBES, 2018). In many regions of Southern Africa, conventional high-input agriculture has not taken hold. In many such regions, resource-poor farmers contend with issues of marginal high-risk environments and experience poor yields just where food security is most vulnerable.

In contending with these issues, other pathways than conventionally intensified agriculture are not just possible but increasingly becoming an imperative in ensuring sustainability. In transforming agriculture in Southern Africa, numerous approaches exist to work with nature, rather than against it, in harnessing key biological processes that sustain and enhance production while also generating other multiple benefits.

These sets of processes are collectively known as "ecosystem services" (ES), defined as "the conditions and processes through which natural ecosystems, and the species that make them up, sustain and fulfil human life" (Daily, 1997). In this chapter we review three which directly underpin agricultural production: soil, pollination and natural pest regulation services. We explore the current state of knowledge of these services, in Southern Africa where possible and beyond where relevant. We ask how farmer access to knowledge of these services can be better promoted and disseminated, given that all of them are knowledge-intensive, rather than input-intensive routes to sustain productivity. And finally, for each ES, we review existing research needs. 


\section{Approaches to harnessing soil ecosystem services in Southern Africa}

For a smallholder farmer in Southern Africa, soil remains a key natural resourcebase for the provision of food production. Soil is fundamental to a wide range of ES - from provisioning services including food, fibre and fuel production, through regulating services (carbon sequestration), cultural services (e.g., building materials, pottery making) and supporting services (source and sink of essential plant growth nutrients) (Millennium Ecosystem Assessment, 2005). Farmers can enhance these services for direct and indirect benefits to their daily livelihoods through agricultural activities.

Agricultural management practices known to positively impact soils and their provisioning of ES include reducing soil disturbance, maintaining ground cover, using organic amendments, optimizing timing and rate of fertilizer application, water management and improved grazing management (reviewed in Smith et al., 2015). The actual mechanism by which practices impact or enhance soil ecosystem services and overall ecosystem resilience is mediated by the response of soil organism to these practices. Targeted management of soil community composition through the concept of soil ecological engineering is a promising approach to enhance agricultural sustainability (Bender et al., 2016). Soil management practices such as cover crops and no-till can impact microbial communities in ways that enhance stress tolerance and resilience (Schmidt et al., 2018).

In Southern Africa, farmers enhance soil productivity by application of organic nutrient resources such as cattle manure, woodland litter, compost and crop residues (Mapfumo and Giller, 2001), practices that in turn boost the soil nutrient reserves and enhance soil quality. To use compost efficiently, attention must be given to the choice of feedstocks and the management of the composting process (Bernal et al., 2017).

Two soil-related ES that have wider societal benefits across a landscape are carbon sequestration and watershed functions. Carbon fixation in agroecosystems is primarily a function of crop type, density and/or mixtures, a common practice in the region. Farmers' practices of soil conservation through organic mulching and/or cover crops (Ngwira et al., 2012) may have positive downstream effects of provision of clean water through erosion control.

Promoting farmer access to knowledge on harnessing soil ecosystem services through policy in Southern Africa: Communities in Southern Africa have long recognized the value of soil ecosystems as reflected in traditional soil management and agricultural production systems and practices. But rising concerns about sustainability of contemporary technologically driven agricultural production systems in the face of land degradation and a decline in the natural resource base upon livelihoods for many rural and peri-urban populations in the world has triggered a strategic research focus on ecosystems services over the last two decades (e.g., Barrios, 2007; Adhikari and Hartemink, 2016). There is a need for global attention to the value of ecosystem services. Three main agricultural approaches in Southern Africa that build on ecosystem services are: 
1 Conservation agriculture (CA), seeking to minimize soil tillage, maximize cover and promote agricultural diversification

2 Integrated soil fertility management (ISFM), seeking to increase soil productivity and achieve more efficient nutrient cycling at field and farm scales through better targeting and allocation of production resources including combinations of organic and inorganic fertilizers, selection of appropriate crop types and varieties and prudent agronomic practices

3 Agro-ecology, seeking to deepen the application of ecological principles in agricultural production systems to harness natural systems and processes otherwise underpinning resilience and sustainability natural ecosystems for the benefit of diversified agriculture

While farmer-centred research and extension approaches hold promise in promoting these knowledge-intensive and complex technical approaches, the response by policymakers has not been consistent and is often still entrenched in top-down agricultural and environmental management policies of "Green Revolution" type production packages, despite their failures in turning the region into a breadbasket case overall. Development of transformative agricultural and environmental policies informed by emerging evidence on the value of soil ecosystem service is a critical work in progress for Southern Africa.

\section{Approaches to managing pollinator forage for pollination services in Southern Africa}

Animal-mediated pollination is a regulating ecosystem service, both for natural ecosystems and for agriculture. The service is provided by pollinators, primarily wild and managed wild bees and other insects. Recent global assessments have stressed the importance of this service, with nearly $90 \%$ of all the flowering plants of the world depending, in part if not entirely, on animal pollination (IPBES, 2016). Declines of pollinators have been noted in many regions, although thorough documentation tends to be limited to Europe and North America. Simultaneously, global agriculture has become increasingly pollinator-dependent (Aizen and Harder, 2009).

The Southern African region encompasses a diversity of environments that support a wide variety of pollinators across various taxa. The abundance, diversity and richness of these taxa depends on their interaction with natural ecosystems whereby requirements tend to differ among species depending on their biology, behaviour and even migration patterns (Chapman et al., 2011).

For forage, both nectar and pollen providing plants need to be both diverse and of high quality throughout the pollinator's life cycle. It is not always possible to secure the full suite of resource needs for pollinators within a farm; for example, some farms have little to no natural vegetation around them to support the pollinators. The forage and nesting requirements for these pollinators will have to be met elsewhere within the surrounding landscapes or adjacent environments. Thus is not always easy to ensure due to competing land uses, 
such as the demand for land to cater for urban development, housing and even expanding agricultural activities that may provide little resources for pollinators (Sayer et al., 2013). Thus, managed pollinators such as honey bees become crucial in providing pollination services for agriculture (Masehela, 2017). Even if their forage needs may be challenged due to environmental pressures, managed honey bees can be moved around in hives over long distances to compensate for lack of forage in certain areas.

Forage for pollinators can be preserved or even enhanced by 1) not burning, cutting or applying herbicides to bee-friendly plants (weeds) unnecessarily and 2) encouraging the planting of multiple crops and trees with good nectar and pollen rewards on farms, in home gardens and in open park spaces. The ultimate goal is for a holistic approach in planning and management that supports and promotes pollinator friendly land use practices at all times.

Promoting farmer access to knowledge on harnessing pollination services through policy in Southern Africa: Agriculture and environmental policies must recognize the importance of pollinators for food production and environmental sustainability. To communicate these values to stakeholders in Southern African, regional examples that resonate with farmers and their daily practices are needed. Key policy messaging should address overall health, habitat requirements and management of pollinators in different landscapes across farm levels. The knowledge and information that farmers need to manage pollinator forage resources both within their farms but also across landscapes needs to be practical and flexible to respond to the many different interfaces of farmers with natural areas. Conveying the rather complex ecological information of managing forage resources across landscapes, in a way that is both timely and scientifically valid, is a challenge. Extension officers, environmental educators, farmer associations and nongovernmental organizations, as key communicators of such messages, need to take into account different literacy levels, language barriers across regions, various forms of media distribution and the relevance and applicability of such knowledge to farmers.

\section{Approaches to managing natural pest control services in Southern Africa}

Biodiversity underpins agricultural ecosystem services and food security, livelihoods and economic development by provisioning natural enemies of crops pests (Gurr et al., 2012). Field margins and non-crop agricultural habitat, if well managed, can provide food (alternative prey and nectar) and refuge for predators and parasitoids, increasing diversity (Bianchi et al., 2006) and abundance (Chaplin-Kramer et al., 2011) of natural enemies and consequently enhances natural pest regulation. Yet, agricultural intensification in Southern Africa has led to biodiversity losses with consequences for the ecosystem services of natural pest control.

Nonetheless, there is substantial evidence that natural pest control services can be enhanced through management practices in Southern Africa. For 
example, natural pest regulation (NPR) of stem borer pests contributes substantial economic benefit to maize production in Southern and East Africa (Midingoyi et al., 2016), while the field release of the ichneumonid wasp Diadegma semiclausum reduced diamondback moth (Plutella xylostella L.) damage on cabbage by $50 \%$ in farms where chemical insecticides were not applied (Kennedy et al., 2016). The role of non-crop habitats in supporting beneficials is less well resolved. One example reported that Tephritid fruit fly abundance increased and rates of parasitism decreased in Mango orchards with distance from non-crop habitats (Henri et al., 2015), although the role of non-crop habitats in supporting longer-term control was not determined.

Landscape heterogeneity can enhance NPR, although the specific drivers still need to be established in order to develop appropriate interventions. For example, in the wine growing areas of the Cape floristic region, old fields provide high plant and prey diversity and subsequently natural enemies (Gaigher et al., 2016a), although this doesn't guarantee natural spill over into adjacent crops (Gaigher et al., 2016b). While natural enemy abundance and NPR are limited by dispersal this could be compensated for by landscape management; it is the quality and complexity of field margins along with the spatial arrangement that facilitate natural enemy dispersal to agricultural land (Griffiths et al., 2008). Synchronization between predator and prey population are also important factors for effective biological control (Macfadyen et al., 2015). Simply enhancing non-crop habitats may not be enough to support NPR. Landscape composition has been shown to explain significant variation in assessed natural enemy and pest abundance, predation rates and crop damage. But while each varied (both increased and decreased) in landscapes with more non-crop habitat, there was no consistent trend (Karp et al., 2018). A better understanding of the impacts of specific interventions and the benefits of specific insects will likely improve the impact of NPR in Southern Africa.

In addition to the dynamics between crops, pests and natural enemies, there are ecological processes occurring within organisms which could be the target of novel forms of biological control. Understanding the microbiome of insects can lead to the development of new sustainable control strategies for pests and strategies to augment the health of beneficial insects. Recent research has indicated, for instance, that symbiont infection can be the difference between invasive and noninvasive insect species; using this knowledge in predicting risks or learning to manipulate such infections in pest populations offers a potential new approach (Himler et al., 2011).

Many crop diseases rely on insect vectors for transmission. Instead of relying on insecticides, it may be possible to block the transmission of diseases by insect vectors by increasing the presence of symbiotic microbes which may be more economical since they are self-sustaining. For example, studies have shown that retention of cassava mosaic begomoviruses (CMBs) was significantly reduced in lines carrying inherited bacterial endosymbionts such as Rickettsia and Arsenophonus compared to controls, and there was an associated reduction in transmission of CMBs - possibly as a consequence of observed elevated immune gene 
expression in the presence of these symbionts (Ghosh et al., 2018). Endosymbiontbased strategies have also been implemented to suppress vector populations. They may as well have a role in supporting populations of beneficial insects. Insect gut microbiota has been shown to have a vital role in host metabolism, protection from parasites and pathogens and modulation of immune responses (Engel and Moran, 2013).

Promoting farmer access to knowledge on managing natural pest control services through policy in Southern Africa: Natural pest regulation (NPR) is a knowledge-intensive pathway to improved pest management and agricultural production that is sustainable and economically viable. Successful implementation is highly dependent on knowledge transfer to farmers and their primary points of contact - often government technical advisers. Therefore, investments in NPR will engage farmers to ensure effective change and resilient agriculture that enhances livelihoods and buffers production against future threats and risks. One major hurdle in promoting ecological intensification that harnesses ecosystem services such as NPR is fundamental knowledge about the natural enemies. It is often challenging for farmers to understand the underlying concept of beneficial insects and to distinguish between good and bad insects let alone understand how land management might influence this service detrimentally (such as field margin clearance). The training of farmers with examples and practical tools can improve understanding about beneficial insects and change how farmers manage field margins (Mkenda et al., in review; Elisante et al., 2019).

\section{Interactions between ecosystem services}

Recent studies also point to interactions between these different ecosystem services, thus suggesting multiple win-wins; for example, there is evidence that soil-born microbes can influence aboveground plant-herbivore interactions, suggesting that soil microbial management could be adapted for pest management strategies (Pineda et al., 2017). Compost application used to remediate degraded soils can enhance the ability of soils to suppress plant pathogens (Pane and Zaccharelli, 2014). Another example of pest management are field margin plants that support natural enemies and pollinators and providing complementary ESs. Another example would be botanical pesticides that have been shown to be effective in promoting NPR in certain pest crop interactions when compared to synthetic pesticides that work against NPR (Mkenda et al., 2015).

\section{Research requirements}

Research needs for the relatively new area of inquiry on ecosystem services underpinning agricultural production systems in Southern Africa are summarized in Table 16.1. The list is indicative, not comprehensive, noting that only $6 \%$ of studies worldwide on ecosystem services have been carried out in Africa to date (Adhikari and Hartemink, 2016). 
Table 16.1 Recommendations for improved impact of ecosystem services in Southern Africa

\begin{tabular}{ll}
\hline Ecosystem service & Research \\
\hline $\begin{array}{c}\text { Soil ecosystem } \\
\text { services }\end{array}$ & $\begin{array}{l}\text { Promotion of soil management recommendations } \\
\text { Support use of diverse and efficient crops and cover crops } \\
\text { Integrate crop breeding and with rhizosphere microbiome } \\
\text { engineering, as a technology on the horizon } \\
\text { Improved support for biofertilizers and biocontrol products }\end{array}$ \\
$\begin{array}{l}\text { Sollination } \\
\text { services }\end{array}$ & $\begin{array}{l}\text { Improve regulation of pesticide use in agricultural landscapes } \\
\text { Natural pest }\end{array}$ \\
regulation & $\begin{array}{l}\text { Support field margin and non-crop habitats improvement } \\
\text { Research insect microbiome dynamics to control pests and } \\
\end{array}$ \\
& enhance health of beneficial insects \\
\hline
\end{tabular}

\section{Conclusion}

Biodiversity and ecosystem services lie at the centre of many solutions for sustainable increases in agricultural productivity that reduce the negative externalities of production and at the same time increase positive externalities - such as watershed protection and creation of biodiversity-friendly habitats on-farm. Throughout these profiles of three key ecosystem services underpinning agricultural production, certain commonalities come to the fore. The functioning of the services in each case is quite complex, and it requires a high level of knowledge on the part of researchers but also of farmers and advisors. There are intriguing areas of interactions and synergies between the services. However, the allocation of funding to such ecologically based solutions, and to the training and dissemination of relevant management practices, has been quite minor in comparison to more technologically based approaches, yet their potential to provide multiple benefits and less environmental costs is substantial.

\section{References}

Adhikari, K. and Hartemink, E. (2016) Linking soils to ecosystem services - A global review. Geoderma, 262, 101-111. https://doi.org/10.1016/j.geoderma.2015.08.009.

Aizen, M.A. and Harder, L.D. (2009) The global stock of domesticated honey bees is growing slower than agricultural demand for pollination. Current Biology, 19(11), 915-918.

Barrios, E. (2007) Soil biota, ecosystem services and land productivity. Ecological Economics, 64(2), 269-285.

Bender, S.F., Wagg, C. and van der Heijden, M.G. (2016) An underground revolution: Biodiversity and soil ecological engineering for agricultural sustainability. Trends in Ecology \& Evolution, 31(6), 440-452.

Bernal, M.P., Sommer, S.G., Chadwick, D., Qing, C., Guoxue, L. and Michel Jr, F.C. (2017) Current approaches and future trends in compost quality criteria for agronomic, environmental, and human health benefits. In Advances in Agronomy (Vol. 144, pp. 143-233). Academic Press. 
Bianchi, F.J.J.A., Booij, C.J.H. and Tscharntke, T. (2006) Sustainable pest regulation in agricultural landscapes: A review on landscape composition, biodiversity and natural pest control. Proc Biol Sci, 273, 1715-1727.

Chaplin-Kramer, R., O’Rourke, M.E., Blitzer, E.J. and Kremen, C. (2011) A meta-analysis of crop pest and natural enemy response to landscape complexity. Ecol Lett, 14, 922-932.

Chapman, B.B., Brönmark, C., Nilsson, J.Å. and Hansson, L.A. (2011) The ecology and evolution of partial migration. Oikos, 120(12), 1764-1775.

Daily, G. (1997) Introduction: What are ecosystem services? In Daily, G., ed. Nature's Services: Societal Dependence on Natural Ecosystems. Washington, DC: Island Press.

Elisante, F. Ndakidemi, P.A., Arnold, S.E.J., Belmain, S.R., Gurr, G.M., Darbyshire, I., Xie, G., Tumbo, J. and Stevenson, P.C. (2019) Knowledge gaps on the role of pollinators and value of field margins among smallholders in bean agri-systems. Journal of Rural Studies, $70,75-86$.

Engel, P. and Moran, N.A. (2013, September) The gut microbiota of insects-diversity in structure and form. FEMS Microbiol Rev. 37(5), 699-735. doi:10.1111/1574-6976.12025.

Gaigher, R., Pryke, J.S. and Samways, M.J. (2016a) High parasitoid diversity in remnant natural vegetation, but limited spillover into the agricultural matrix in South African vineyard agroecosystems. Biological Conservation, 186, 69-74.

Gaigher, R.J.S. and Samways, M.J. (2016b) Old fields increase habitat heterogeneity for arthropod natural enemies in an agricultural mosaic. Agriculture Ecosystems and Environment, 230, 242-250.

Ghosh, S., Bouvaine, S., Richardson, S.C.W., Ghanim, M. and Maruthi, M.N. (2018) Fitness costs associated with infections of secondary endosymbionts in the cassava whitefly species. J. Pest Sci, 91(1), 17-28.

Griffiths, G.J.K., Holland, J.M., Bailey, A. and Thomas, M.B., (2008) Efficacy and economics of shelter habitats for conservation biological control. Biological Control, 45, 200-209.

Gurr, G.M., Wratten, S.D. and Snyder, W.E. (eds) (2012) Biodiversity and Insect Pest Management: Key Issues for Sustainable Management. West Sussex: Wiley.

Henri, D.C., Jones, O., Tsiattalos, A., Thebault, E., Seymour, C.L. and van Veen, F.J.F. (2015) Natural vegetation benefits synergistic control of the three main insect and pathogen pests of a fruit crop in southern Africa. Journal of Applied Ecology, 52, 1092-1101.

Himler, A.G., Adachi-Hagimor, T., Bergen, J.E., Kozuch, A., Kelly, S.E., Tabashnik, B.E., Chief, E., Duckworth, V.E., Dennely, T.J., Zchori-Fein, E. and Hunter, M.S. (2011) Rapid spread of a bacterial symbiont in an invasive whitefly is driven by fitness benefits and female bias. Science, 332(6026), 254-256.

IPBES. (2016) Assessment Report on Pollinators, Pollination and Food Production. Bonn, Germany: UN Intergovernmental Platform on Biodiversity and Ecosystem Services.

IPBES. (2018) Summary report, Land Degradation. Bonn, Germany: UN Intergovernmental Platform on Biodiversity and Ecosystem Services.

Karp, D.S. et al. (2018) Crop pests and predators exhibit inconsistent responses to surrounding landscape composition. PNAS, 115, E7863-E7870.

Kennedy, C.M. et al. (2016) A global quantitative synthesis of local and landscape effects on wild bee pollinators in agroecosystems. Ecol. Lett., 16, 584-599.

Macfadyen, S., Hopkinson, J., Parry, H., Neave, M.J., Bianchi, F.J.J.A., Zalucki, M.P. and Schellhorn, N.A. (2015) Early-season movement dynamics of phytophagous pest and natural enemies across a native vegetation-crop ecotone. Agriculture, Ecosystems and Environment, 200, 110-118.

Mapfumo, P. and Giller, K.E. (2001) Soil Fertility Management Strategies and Practices by Smallholder Farmers in Semi-Arid Areas of Zimbabwe. International Crops Research Institute for 
the Semi-Arid Tropics (ICRISAT)/ Food and Agriculture Organization of the United Nations (FAO), 60p.

Masehela, T.S. (2017) An assessment of different beekeeping practices in South Africa based on their needs (bee forage use), services (pollination services) and threats (hive theft and vandalism) (Doctoral dissertation, Stellenbosch: Stellenbosch University).

Midingoyi, S., Affognon, H.D., Macharia, I., Ong'amo, G., Abonyo, E., Ogola, G., De Groote, H. and LeRu, B. (2016) Assessing the long-term welfare effects of the biological control of cereal stemborer pests in East and Southern Africa: Evidence from Kenya, Mozambique and Zambia. Agriculture, Ecosystems and Environment 230, 10-23.

Millennium Ecosystem Assessment. (2005) Ecosystems and Human Well-Being: Synthesis Report. Washington, DC: Island Press.

Mkenda, P., Mwanauta, R., Stevenson, P.C., Ndakidemi, P., Mtei, K. and Belmain, S.R. (2015) Field margin weeds provide economically viable and environmentally benign pest control compared to synthetic pesticides. PLoS One, 10, e0143530.

Ngwira, R.A., Thierfelder, C. and Lambert, D.M. (2012) Conservation agriculture systems for Malawian smallholder farmers: Long-term effects on crop productivity and soil quality. Renewable Food Systems. doi:10.1017/S1742170512000257.

Pane, C. and Zaccardelli, M. (2014) Principles of compost-based plant diseases control and innovative new developments. In Composting for Sustainable Agriculture (pp. 151-171). Cham: Springer.

Pineda, A., Kaplan, I. and Bezemer, T.M. (2017) Steering soil microbiomes to suppress aboveground insect pests. Trends in Plant Science, 22(9), 770-778.

Sayer, J., Sunderland, T., Ghazoul, J., Pfund, J.L., Sheil, D., Meijaard, E., Venter, M., Boedhihartono, A.K., Day, M., Garcia, C. and van Oosten, C. (2013) Ten principles for a landscape approach to reconciling agriculture, conservation, and other competing land uses. Proc. Nat. Acad. Sci., 110(21), 8349-8356.

Schmidt, R., Gravuer, K., Bossange, A.V., Mitchell, J. and Scow, K. (2018) Long-term use of cover crops and no-till shift soil microbial community life strategies in agricultural soil. PloS One, 13(2), e0192953.

Smith, P., Cotrufo, M.F., Rumpel, C., Paustian, K., Kuikman, P.J., Elliott, J.A., McDowell, R., Griffiths, R.I., Asakawa, S., Bustamante, M., House, J.I., Sobocká, J., Harper, R., Pan, G., West, P.C., Gerber, J.S., Clark, J.M., Adhya, T., Scholes, R.J. and Scholes, M.C. (2015) Biogeochemical cycles and biodiversity as key drivers of ecosystem services provided by soils. SOIL Discussions, 2(1), 537-586. 